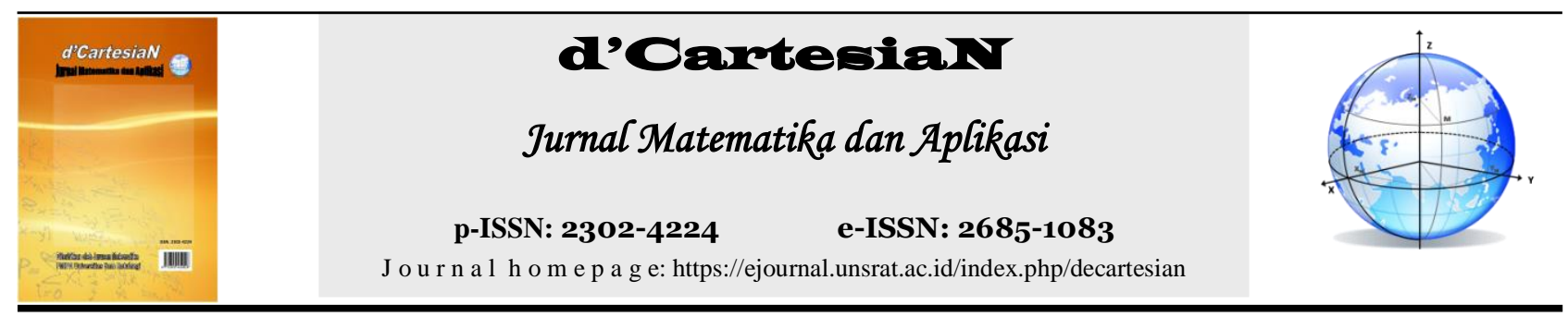

\title{
Model Three-Level Dual-Channel Supply Chain pada Sistem Sentralisasi dengan Memertimbangkan Waktu Tunggu Pengiriman
}

\author{
Shinta Nur Pratiwi Ramadhani ${ }^{1}$, Ririn Setiyowati ${ }^{1}$, Titin Sri Martini ${ }^{1}$ \\ ${ }^{1}$ Program Studi Matematika, Fakultas Matematika dan Ilmu Pengetahuan Alam, Universitas Sebelas Maret Surakarta, Indonesia \\ *Corressponding author: shintanpr@student.uns.ac.id
}

\begin{abstract}
A B S T R A K
Era pasar global telah mengubah kebiasaan konsumen dalam membeli produk, sehingga konsumen dapat membeli produk melalui media online. Oleh karena itu, produsen mengembangkan media penjualannya melalui media online dan offline. Pada penelitian ini dikembangkan model threelevel dual-channel supply chain dengan memertimbangkan waktu tunggu pengiriman pada penjualan melalui media online yang dilakukan oleh produsen serta mengembangkan media penjualan distributor sehingga distributor dapat menjual produk secara langsung ke konsumen. Konstruksi model bertujuan untuk mengoptimalkan keuntungan gabungan produsen, distributor, dan pengecer dengan sistem sentralisasi. Fungsi keuntungan gabungan merupakan fungsi nonlinear tanpa kendala dengan tiga variabel keputusan yaitu harga jual produsen pada media online, harga jual distributor langsung ke konsumen, dan harga jual pengecer ke konsumen. Selanjutnya, ditentukan solusi optimal model berdasarkan syarat perlu dan syarat cukup untuk fungsi multivariabel tanpa kendala. Hasil simulasi numerik dan analisis sensitivitas menunjukkan adanya pengaruh waktu tunggu pengiriman terhadap fungsi keuntungan gabungan yang optimal. Selain itu lamanya waktu tunggu pengiriman sangat berpengaruh pada besarnya keuntungan optimal produsen, distributor, dan pengecer.
\end{abstract}

\section{INFO ARTIKEL}

Diterima : 1 Februari 2020

Diterima setelah revisi : 7 Maret 2020

Tersedia online : 15 Maret 2020

Kata Kunci:

Sentralisasi,

Three-Level,

Waktu Tunggu

\section{A B S T R A C T}

The global market era changes the consumer behavior to shop the product, so the consumer can buy through online channel. Therefore, the producer develop the selling channel to sell their products through online channel and offline channel. In this research, we develop the three-level dual-channel supply chain by notice delivery lead time in the online channel used by the producer and develop selling channel from distributors so distributors can sell their product to consumer with direct selling. We construct the model with profit maximization motive of the system that consists producer, distributors, and retailer in the centralize system. The total profit function is nonlinear function without constrains with three decision variables. Furthermore, we determine the optimal solution of the model based on necessary and sufficient condition. Numerical simulations and sensitivity analysis show that the delivery lead time strongly influences the optimal total profit system. In addition, the delivery lead time strongly influences the optimal profit of manufacturer, distrbutors, and retailers.

\section{ARTICLE INFO}

Received : 1 February 2020

Received in revised : 7 March 2020

Available online : 15 March 2020

\section{Keywords:}

Centralize,

Lead Time,

Three-Level

\section{PENDAHULUAN}

Perkembangan teknologi di era digital telah mengubah pola pembelian konsumen yang menyebabkan produsen mengembangkan struktur media penjualannya untuk menjangkau segmen pasar secara luas. Menurut Linton et al. [8] untuk mencapai segmen pasar yang lebih luas dapat dilakukan dengan strategi ketahanan perusahaan yang diperkuat melalui supply chain. Bilgen [2] menyebutkan bahwa supply chain management (SCM) adalah sistem terintegrasi yang meliputi pembelian, pembuatan, penyimpanan, distribusi, dan pengelolaan produk. Disebutkan oleh Choi [4] bahwa penjualan produk menggunakan media online dapat memperluas segmen pasar, mengontrol harga produk, dan meningkatkan laba. Menurut Kumar et al. [7], supply chain dengan proses distribusi produk melalui media offline dan media online disebut dengan dual-channel supply chain. Model dual-channel supply 
chain dapat memberikan banyak pilihan belanja dan harga yang lebih murah kepada konsumen sehingga konsumen cenderung memilih produsen yang menjual produk melalui media online dan offline. Oleh karena itu, Hanover [5] menyebutkan bahwa produsen perlu mengembangkan dual-channel supply chain.

Produsen yang menjual produk menggunakan media online pada dual-channel supply chain erat kaitannya dengan waktu pengiriman karena waktu pengiriman. Urban et al. [13] pada penelitiannya menyebutkan bahwa waktu tunggu pengiriman adalah durasi ketika pelanggan memesan produk ke waktu menerima produk, yang mencakup waktu pesanan, waktu pengumpulan dan waktu pengiriman dari gudang ke pelanggan. Waktu tunggu pengiriman menjadi ukuran penting untuk kualitas layanan dari media online. Waktu tunggu pengiriman menyebabkan beberapa dampak, jika waktu tunggu pengiriman pendek maka biaya logistik meningkat dan markup margin berkurang. Berdasarkan penelitian Hua et al. [6], jika pengiriman membutuhkan waktu lama maka loyalitas konsumen terhadap media online berkurang. Waktu tunggu pengiriman pada dual-channel supply chain memiliki efek pada keuntungan sistem atau keuntungan setiap bagian yang terlibat dalam dualchannel supply chain.

Struktur DCSC pada umumnya terdiri dari dua level yaitu produsen dan pengecer. Produsen menjual produk ke pengecer dan selanjutnya pengecer menjual produk ke konsumen. Namun, perkembangan bidang ekonomi industri yang semakin pesat menyebabkan perubahan struktur supply chain yang semula terdiri dari dua level menjadi tiga level. Modak et al. [9] mengembangkan three-echelon dual-channel supply chain yang terdiri dari produsen, distributor, dan pengecer dengan produsen menggunakan dua media penjualan online dan offline. Disamping model tersebut para ahli juga mengembangkan model three-level dualchannel supply chain dengan struktur yang berbedabeda. Saha et al. [11] mengembangkan tiga struktur media penjualan yang berbeda pada three-level dualchannel supply chain, yaitu pengecer yang menggunakan offline channel, produsen yang menggunakan offline channel dan online channel, serta pengecer yang menggunakan offline channel dan online channel.

Dalam penelitian ini, akan dikonstruksikan model three-level dual-channel supply chain dengan memertimbangkan waktu tunggu pengiriman. Produsen menjual produk ke konsumen melalui media online dan ke distributor melalui media offline, dan kemudian distributor menjual produk ke konsumen dan pengecer dengan media offline, serta pengecer menjual produk ke konsumen melalui media offline. Pada penelitian ini memertimbangkan waktu tunggu pengiriman karena pada media online waktu tunggu pengiriman dapat mempengaruhi keuntungan optimal dari sistem. Tujuan dari penelitian ini adalah untuk memaksimalkan keuntungan sistem yang terdiri dari produsen, distributor, dan pengecer. Pada penelitian ini ditentukan harga jual optimal dari produsen pada media online, harga jual distributor langsung ke konsumen, dan harga jual pengecer ke konsumen sehingga diperoleh total keuntungan sistem yang optimal.

\section{TINJAUAN PUSTAKA}

Kesadaran bahwa internet memiliki peluang besar untuk menjangkau segmen konsumen yang lebih luas telah menyebabkan banyak produsen mengembangkan media penjualannya melalui media online. Pada media online, waktu tunggu pengiriman adalah faktor penting dalam keputusan penentuan harga untuk menentukan harga dalam supply chain management. Pekgun et al. [10], dalam penelitiannya tentang keputusan penetapan harga dan waktu tunggu pengiriman yang dilakukan oleh departemen produksi dan pemasaran, mengasumsikan bahwa konsumennya homogen dan hasilnya menunjukkan bahwa jika waktu tunggu lama harga akan lebih rendah, dan menyebabkan permintaan total yang lebih besar.

Hua [6] menyebutkan bahwa perbedaan permintaan antara media offline dan online dengan memertimbangkan waktu tunggu pengiriman, harga jual dari penjualan secara langsung, dan pendapatan konsumen dari penjualan secara langsung memiliki pengaruh signifikan terhadap keputusan penetapan harga. Pada tahun 2012 dilakukan penelitian oleh Chen et al. [3] tentang strategi keputusan harga produsen pada dual-channel supply chain, jika ada perjanjian yang dibuat oleh produsen mengenai harga grosir dan harga jual dalam penjualan secara langsung, hal ini dapat mengkoordinasikan dual-channel supply chain. Dilakukan penelitian tentang keputusan penetapan harga dan hasilnya menunjukkan bahwa layanan penjualan ritel memiliki dampak besar pada strategi keputusan penetapan harga kepada produsen dan pengecer. Jika tidak, harga dari pengecer dan penjualan secara langsung sangat dipengaruhi oleh loyalitas konsumen dalam penjualan ritel dan peningkatan rasio permintaan pada kedua media yang memperhatikan layanan penjualan ritel. Menurut Zhang et al. [12] hal ini mempengaruhi keuntungan di media penjualan tersebut. Strategi untuk mengoptimalkan keuntungan telah diteliti oleh Batarfi et al. [1], ditunjukkan bahwa struktur dual-channel memiliki keuntungan yang lebih besar daripada struktur single-channel. Dalam struktur dual-channel produsen dapat memperoleh markup margin dan mendapatkan keuntungan tinggi. Selain itu, keuntungan pengecer menurun karena permintaan menurun. Penelitian menunjukkan bahwa tingkat penerimaan pelanggan dari media online, waktu pengiriman, dan pengaruh perubahan harga pada jumlah permintaan produk memiliki dampak besar pada total keuntungan pada struktur dual-channel.

Saha et al. [11] melakukan studi tentang dualchannel supply chain di mana ada tiga struktur, yaitu manufacturer's dual-channel, retailer's dual-channel, dan single-retail channel. Dalam penelitian tersebut, dibuat analisis dan perbandingan ketiga struktur tersebut. Melalui perbandingan manfaat dari dua dualchannel dengan single-retail channel, teridentifikasi bahwa dual-channel tidak menguntungkan jika menggunakan non-cooperative scenario. Oleh karena itu, produsen, distributor dan pengecer bersama-sama membuat keputusan terpusat untuk menentukan harga eceran dan harga jual dalam penjualan secara langsung dengan tujuan untuk mengoptimalkan total keuntungan supply chain.

\section{METODE PENELITIAN}

Metode penelitian yang digunakan dalam penelitian ini adalah studi literatur mengenai three-level dual-channel supply chain kemudian dilakukan pengembangan model dengan menambahkan media penjualan distributor dan memertimbangkan waktu 
tunggu pengiriman lalu dilakukan analisis. Langkahlangkah yang dilakukan dalam penelitian ini yaitu

1. mempelajari penelitian yang sudah ada mengenai model three-level dual-channel supply chain,

2. menentukan asumsi model three-level dualchannel supply chain yang akan dikembangkan,

3. menentukan fungsi tujuan berupa fungsi keuntungan dengan mengonstruksi fungsi permintaan, pendapatan total, dan biaya total pada produsen, distributor dan pengecer,

4. membuktikan model memiliki penyelesaian optimal,

5. menentukan penyelesaian optimal untuk model three-level dual-channel supply chain yang memertimbangkan waktu tunggu pengiriman,

6. menentukan parameter yang sesuai kemudian dilakukan simulasi numerik,

7. mengubah parameter waktu tunggu pengiriman untuk menganalisis pengaruh waktu tunggu pengiriman terhadap keuntungan optimal.

\section{HASIL DAN PEMBAHASAN}

Diuraikan model three-level dual-channel supply chain yang terdiri dari produsen, distributor dan pengecer. Diasumsikan bahwa produsen, distributor dan pengecer menjual produk standar. Produsen menjual kepada distributor melalui media offline dan kepada konsumen melalui media online. Distributor menjual produk ke pengecer dan konsumen melalui media offline, dan kemudian pengecer menjual produk ke konsumen melalui media offline.

\subsection{Asumsi} ini.

Berikut asumsi yang digunakan dalam penelitian

1. Jumlah produk yang diproduksi oleh produsen sama dengan jumlah permintaan, sehingga tidak terjadi kekurangan produk dan tidak terdapat biaya penyimpanan.

2. Harga grosir produk pada produsen lebih besar dari biaya produksi produk dan lebih kecil dari harga grosir produk pada distributor sehingga $c_{m}<w_{m}<w_{d}$.

3. Produsen menjual produk ke konsumen melalui media online dengan harga $p_{m}$, distributor dan pengecer menjual produk ke konsumen melalui media offline berturut-turut dengan harga $p_{d}$ dan $p_{r}$.

4. Perubahan permintaan tiap pelaku dipengaruhi adanya perubahan harga jual masing-masing pelaku yang digambarkan dengan parameter elastisitas harga produk $\beta_{i}, i=m, d, r$ dengan $m$ menggambarkan produsen, $d$ menggambarkan distributor dan $r$ menggambarkan pengecer.

5. Permintaan konsumen tiap pelaku dipengaruhi oleh perubahan harga jual antara kedua media penjualan yang digambarkan dengan parameter sensitivitas harga silang antara media online dan offline sebesar $s_{j}, j=d, r$.

6. Pengaruh harga silang antar pelaku pada media offline diabaikan.

7. Waktu tunggu antara distributor dengan produsen, distributor dengan pengecer, serta konsumen dengan distributor maupun pengecer adalah nol.

8. Penjualan produk dari produsen melalui media online memertimbangkan faktor waktu tunggu pengiriman produk yang disimbolkan dengan $l$.

9. Prioritas konsumen dalam membeli produk melalui media online dipengaruhi oleh lamanya waktu tunggu pengiriman produk, perpindahan jumlah permintaan konsumen dari media online ke media offline sesuai dengan parameter sensitivitas waktu tunggu pengiriman sebesar $\gamma_{j}, j=d, r$.

10. Diasumsikan bahwa min $\left\{\beta_{m}, \beta_{d}, \beta_{r}\right\}>$ maks $\left\{s_{d}, s_{r}, \gamma_{d}, \gamma_{r}\right\}$

11. Proses produksi yang dilakukan produsen tidak terdapat produk cacat sehingga tidak memerhatikan faktor pengembalian produk.

\subsection{Fungsi Permintaan}

Potensi permintaan pasar pada media online yang dilakukan oleh produsen adalah $a_{m}$ dan dari media offline pada distributor adalah $a_{d}$, serta pada pengecer adalah $a_{r}$. Diasumsikan bahwa fungsi permintaan linier dengan elastisitas harga $\beta_{m}$ pada produsen, $\beta_{d}$ di distributor, dan $r$ di pengecer. Fungsi permintaan dipengaruhi oleh sensitivitas harga silang antara media online dan offline dengan sensitivitas $s_{d}$ pada distributor dan $s_{r}$ di pengecer. Diasumsukan bahwa fungsi permintaan linear terhadap waktu pengiriman. Waktu tunggu pengiriman dapat mengubah kecenderungan konsumen dalam membeli produk di media online yang dilambangkan dengan $l$. Lamanya waktu tunggu pengiriman di media online berpengaruh pada unit permintaan dengan sensitivitas waktu tunggu pengiriman $\gamma_{d}$ di distributor dan $\gamma_{r}$ di pengecer. Fungsi permintaan di produsen dilambangkan dengan $D_{m}$, di distributor dilambangkan dengan $D_{d}$ dan di pengecer dilambangkan dengan $D_{r}$. Dengan demikian, fungsi permintaan dirumuskan sebagai berikut:

$$
\begin{gathered}
D_{m}=a_{m}-\beta_{m} p_{m}+s_{d} p_{d}+ \\
s_{r} p_{r}-\left(\gamma_{d}+\gamma_{r}\right) l \\
D_{d}=a_{d}-\beta_{d} p_{d}+s_{d} p_{d}+\gamma_{d} l \\
D_{r}=a_{r}-\beta_{r} p_{r}+s_{r} p_{r}+\gamma_{r} l
\end{gathered}
$$

\subsection{Fungsi Keuntungan Produsen}

Penjualan produk dari produsen melalui media online dan offline, sehingga fungsi keuntungan dari produsen adalah jumlah dari keuntungan online dan offline. Jumlah biaya produsen diperoleh dari biaya produksi $c_{m}$ dikalikan permintaan konsumen dari produsen pada media online dan permintaan konsumen dari distributor pada media offline. Berdasarkan persamaan (1), (2), dan (3) biaya produsen dilambangkan dengan $T C_{m}$, pendapatan produsen 
dilambangkan dengan $T R_{m}$, dan fungsi keuntungan produsen dilambangkan dengan $\Pi_{m}$ sehingga dapat dirumuskan sebagai berikut

$$
\begin{aligned}
T C_{m}= & c_{m}\left(D_{m}+D_{d}+D_{r}\right) \\
T R_{m}= & p_{m} D_{m}+w_{m}\left(D_{d}+D_{r}\right) \\
\Pi_{m}= & \left(p_{m}-c_{m}\right) D_{m}+\left(w_{m}-\right. \\
& \left.c_{m}\right)\left(D_{d}+D_{r}\right) .
\end{aligned}
$$

\subsection{Fungsi Keuntungan Distributor}

Total biaya distributor diperoleh dari harga grosir pada produsen $w_{m}$ dengan nilai $w_{m}=\mu p_{m}$. Biaya ini dikalikan dengan fungsi permintaan distributor yang diperoleh dari jumlah permintaan pada penjualan secara langsung ke konsumen dan ke pengecer. Berdasarkan persamaan (1), (2), dan (3), biaya distributor yang dilambangkan dengan $T C_{d}$, pendapatan distributor dilambangkan dengan $T R_{d}$, dan fungsi keuntungan dari distributor yang dilambangkan dengan $\Pi_{d}$ dapat dirumuskan sebagai berikut

$$
\begin{aligned}
& T C_{d}=w_{m}\left(D_{d}+D_{r}\right) \\
& T R_{d}=w_{d} D_{r}+p_{d} D_{d} \\
& \begin{aligned}
\Pi_{d} & =\left(w_{d}-w_{m}\right) D_{r}+\left(p_{d}-\right. \\
& \left.w_{m}\right) D_{d} .
\end{aligned}
\end{aligned}
$$

\subsection{Fungsi Keuntungan Pengecer}

Total biaya pengecer diperoleh dari harga grosir pada distributor $w_{d}$ dengan nilai $w_{d}=\delta p_{d}$. Biaya ini dikalikan dengan fungsi permintaan pengecer yang diperoleh dari jumlah permintaan pada penjualan secara langsung ke konsumen. Berdasarkan persamaan (1), (2), dan (3), biaya pengecer yang dilambangkan dengan $T C_{r}$, pendapatan pengecer dilambangkan dengan $T R_{r}$, dan fungsi keuntungan dari pengecer yang dilambangkan dengan $\Pi_{r}$ dapat dirumuskan sebagai berikut

$$
\begin{aligned}
& T C_{r}=w_{d} D_{r} \\
& T R_{r}=p_{r} D_{r} \\
& \Pi_{r}=\left(p_{r}-w_{d}\right) D_{r} .
\end{aligned}
$$

\subsection{Model Three-Level Dual-Channel Supply Chain dengan Memertimbangkan Waktu Tunggu Pengiriman \\ Model three-level dual-channel supply chain} merupakan keuntungan gabungan dari keuntungan produsen, distributor dan pengecer berdasarkan persamaan (4), (5) dan (6). Jadi, dapat dirumuskan model matematika dari three-level dual-channel supply chain dengan memertimbangkan waktu tunggu pengiriman yaitu sebagai berikut

maks, $\Pi_{c}\left(p_{m}, p_{d}, p_{r}\right)=\left(p_{m}-c_{m}\right) D_{m}+\left(w_{m}-c_{m}\right)\left(D_{d}+D_{r}\right)$ $+\left(w_{d}-w_{m}\right) D_{r}+\left(p_{d}-w_{m}\right) D_{d}+\left(p_{r}-w_{d}\right) D_{r}$.

\subsection{Solusi Optimal}

Sebelum menentukan solusi optimal, terlebih dahulu dibuktikan bahwa fungsi keuntungan gabungan dar modeli three-level dual-channel supply chain adalah fungsi konkaf tegas. Oleh karena itu, ditentukan matriks Hessian dari fungsi $\Pi_{c}$ adalah

$$
H\left(\Pi_{c}\right)=\left(\begin{array}{ccc}
-2 \beta_{m} & 2 s_{d} & 2 s_{r} \\
2 s_{d} & -2 \beta_{d} & 0 \\
2 s_{r} & 0 & -2 \beta_{r}
\end{array}\right)
$$

berdasarkan matriks Hessian, dapat ditentukan principal minor determinan sebagai berikut

$$
\begin{gathered}
\left|\mathrm{H}_{11}\right|=-2 \beta_{m}, \\
\left|\mathrm{H}_{22}\right|=4 \beta_{d} \beta_{m}-4 s_{d}^{2}, \\
\left|\mathrm{H}_{33}\right|=8\left(s_{r}^{2} \beta_{d}+\left(s_{d}^{2}-\beta_{d} \beta_{m}\right) \beta_{r}\right)
\end{gathered}
$$

berdasarkan asumsi ke-9 dapat diperoleh nilai persamaan (8), (9), dan (10) yaitu $\left|H_{11}\right|<0,\left|H_{22}\right|>0$, $\left|H_{33}\right|<0$ sehingga dapat disimpulkan bahwa $\Pi_{c}\left(p_{m}, p_{d}, p_{r}\right)$ adalah fungsi konkaf tegas.

Keuntungan sistem dari three-level dualchannel supply chain adalah fungsi konkaf tegas. Jadi, hanya ada satu solusi optimal $\left(p_{m}, p_{d}, p_{r}\right)$ yang menghasilkan nilai maksimal $\Pi_{c}\left(p_{m}, p_{d}, p_{r}\right)$. Model matematika pada persamaan (7) adalah masalah optimisasi tanpa kendala. Solusi untuk model adalah menyelesaikan turunan parsial dari keuntungan gabungan terhadap $\left(p_{m}, p_{d}, p_{r}\right)$ yang kemudian dibuat

\begin{tabular}{|c|c|c|c|}
\hline Parameter & Nilai & Parameter & Nilai \\
\hline$a_{m}$ & $\begin{array}{c}1000 \\
\text { unit/tahun }\end{array}$ & $\beta_{m}$ & $\begin{array}{c}0.1 \\
\text { unit }^{2} / \$ / \text { tahun }\end{array}$ \\
\hline$a_{d}$ & $\begin{array}{c}1500 \\
\text { unit/tahun }\end{array}$ & $\beta_{d}$ & $\begin{array}{c}0.3 \\
\text { unit }^{2} / \$ / \text { tahun }\end{array}$ \\
\hline$a_{r}$ & $\begin{array}{c}2000 \\
\text { unit/tahun }\end{array}$ & $\beta_{(7)}$ & $\begin{array}{c}0.4 \\
\text { unit }^{2} / \$ / \text { tahun }\end{array}$ \\
\hline$\gamma_{d}$ & $\begin{array}{c}\text { o.01 } \\
\text { unit/hari }\end{array}$ & $s_{d}$ & 0.05 \\
\hline$\gamma_{r}$ & $\begin{array}{c}\text { o.01 } \\
\text { unit/hari }\end{array}$ & $s_{r}$ & 0.05 \\
\hline$c_{m}$ & \$/unit & $l$ & $\begin{array}{c}6 \\
\text { hari }\end{array}$ \\
\hline
\end{tabular}
sama dengan o, sehingga diperoleh

$$
\begin{gathered}
a_{m}+2 p_{d} s_{d}+2 p_{r} s_{r}-c_{m}\left(s_{d}+s_{r}-\beta_{m}\right)-2 p_{m} \beta_{m} \\
-l\left(\gamma_{d}+\gamma_{r}\right)=0 \\
a_{d}+2 p_{m} s_{d}+c_{m}\left(-s_{d}+\beta_{d}\right)-2 p_{d} \beta_{d}+l \gamma_{d}=0 \\
a_{r}+2 p_{m} s_{r}-c_{m}\left(s_{r}-\beta_{r}\right)-2 p_{r} \beta_{r}+l \gamma_{r}=0 \\
\text { Berdasarkan turunan parsial dari keuntungan }
\end{gathered}
$$
gabungan terhadap $\left(p_{m}, p_{d}, p_{r}\right)$ dapat ditentukan solusi optimal untuk memperoleh keuntungan gabungan yang maksimal menggunakan metode Cramer. Diperoleh solusi optimal $\left(p_{m}, p_{d}, p_{r}\right)$ adalah

$$
\begin{aligned}
& p_{m}^{*}=\frac{-a_{r} s_{r} \beta_{d}+x_{1}-\beta_{r} x_{2}+l \beta_{d}\left(-s_{r}+\beta_{r}\right) \gamma_{r}}{2\left(s_{r}^{2} \beta_{d}+\left(s_{d}^{2}-\beta_{d} \beta_{m}\right) \beta_{r}\right)} \\
& p_{d}^{*}=\frac{-a_{r} s_{d} s_{r}-a_{m} s_{d} \beta_{r}+x_{1}+a_{d}\left(s_{r}^{2}-\beta_{m} \beta_{r}\right)+x_{3}}{2\left(s_{r}^{2} \beta_{d}+\left(s_{d}^{2}-\beta_{d} \beta_{m}\right) \beta_{r}\right)} \\
& p_{r}^{*}=\frac{-a_{d} s_{d} s_{r}-a_{m} s_{r} \beta_{d}+x_{1}+a_{r}\left(s_{d}^{2}-\beta_{m} \beta_{d}\right)-x_{4}}{2\left(s_{r}^{2} \beta_{d}+\left(s_{d}^{2}-\beta_{d} \beta_{m}\right) \beta_{r}\right)} \\
& \text { dengan nilai } x_{1}-x_{4} \text { sebagai berikut } \\
& x_{1}=c_{m}\left(s_{r}^{2} \beta_{d}+s_{d}^{2} \beta_{r}-\beta_{r} \beta_{d} \beta_{m}\right) \\
& x_{2}=a_{d} s_{d}+a_{m} \beta_{d}+l\left(s_{d}-\beta_{d}\right) \gamma_{d} \\
& x_{3}=l s_{r}^{2} \gamma_{d}+l s_{d} \beta_{r} \gamma_{d}-l \gamma_{d} \beta_{m} \beta_{r}-l s_{d} s_{r} \gamma_{r}+ \\
& \quad l s_{d} \beta_{r} \gamma_{r} \\
& x_{4}=l s_{d} s_{r} \gamma_{d}+l s_{r} \beta_{d} \gamma_{d}+l\left(s_{d}^{2}+s_{r} \beta_{d}-\beta_{m} \beta_{d}\right) \gamma_{r} .
\end{aligned}
$$

\subsection{Simulasi Numerik}

Solusi yang diperoleh dilakukan pendekatan dengan melakukan simulasi numerik model three-level dual-channel supply chain pada sistem sentralisasi. Nilai parameter yang digunakan diuraikan dalam Tabel 1.

Tabel 1. Nilai Parameter 
Berdasarkan simulasi numerik, diperoleh solusi optimal untuk model three-level dual-channel supply chain pada sistem sentralisasi dengan memertimbangkan waktu tunggu pengiriman yang dirangkum dalam Tabel 2.

Tabel 2. Solusi Optimal dari Model Three-Level DualChannel Supply Chain

\begin{tabular}{ccccccc}
\hline$p_{m}^{*}$ & $p_{d}^{*}$ & $p_{r}^{*}$ & $\Pi_{m}^{*}$ & $\Pi_{d}^{*}$ & $\Pi_{r}^{*}$ & $\Pi_{c}^{*}$ \\
$(\$)$ & $(\$)$ & $(\$)$ & $(\$)$ & $(\$)$ & $(\$)$ & $(\$)$ \\
\hline 8792 & 397 & 3610 & 1046 & 403 & 3159 & 10903 \\
.39 & 5.91 & .06 & 8100 & 901 & 9.9 & 600 \\
\hline
\end{tabular}

Setelah diperoleh simulasi numerik kemudian dilakukan analisis sensitivitas untuk mengetahui factor yang dipertimbangkan dalam model terhadap solusi optimalnya.

\subsection{Analisis Sensitivitas}

Analisis sensitivitas faktor waktu tunggu pengiriman (l) dilakukan untuk mengetahui pengaruhnya terhadap keuntungan optimal . Hasil analisis sensitivitas terlihat dalam Gambar 1.

Hasil analisis sensitivitas parameter waktu tunggu pengiriman menunjukkan bahwa semakin lama waktu tunggu pengiriman barang dari produsen pada media online menyebabkan keuntungan produsen semakin kecil. Sebaliknya, keuntungan distributor dan pengecer semakin besar.

\section{KESIMPULAN DAN SARAN}

Penelitian ini menjelaskan tentang model threelevel dual-channel supply chain dengan produsen, distributor, dan pengecer menentukan solusi optimal melalui system sentralisasi untuk mendapatkan keuntungan gabungan yang maksimal, pada model ini dipertimbangkan factor waktu tunggu pengiriman barang yang dijual melalui media online. Berdasarkan simulasi numerik diperoleh keuntungan gabungan yang optimal sebesar \$10903600, dengan harga jual dari produsen pada media online sebesar $\$ 8792.39$, harga jual dari distributor langsung ke konsumen sebesar \$3975.91 dan harga jual pengecer ke konsumen sebesar \$3610.06. Berdasarkan analisi sensitivitas, jika parameter waktu tunggu pengiriman dilakukan perubahan dan parameter yang lainnya tetap maka diperoleh bahwa semakin lama waktu tunggu pengiriman barang dari produsen pada media online menyebabkan keuntungan produsen semakin kecil. Sebaliknya, keuntungan distributor dan pengecer semakin besar, sehingga keuntungan gabungan semakin kecil ketika waktu tunggu pengiriman semakin lama.

Penelitian lanjutan dapat dilakukan dengan menambahkan faktor pemberian harga diskon dengan n-pelaku, serta dapat memertimbangkan proses remanufacturing, refurbishing, dan inspeksi sehingga model dapat lebih mendekati kenyataan.
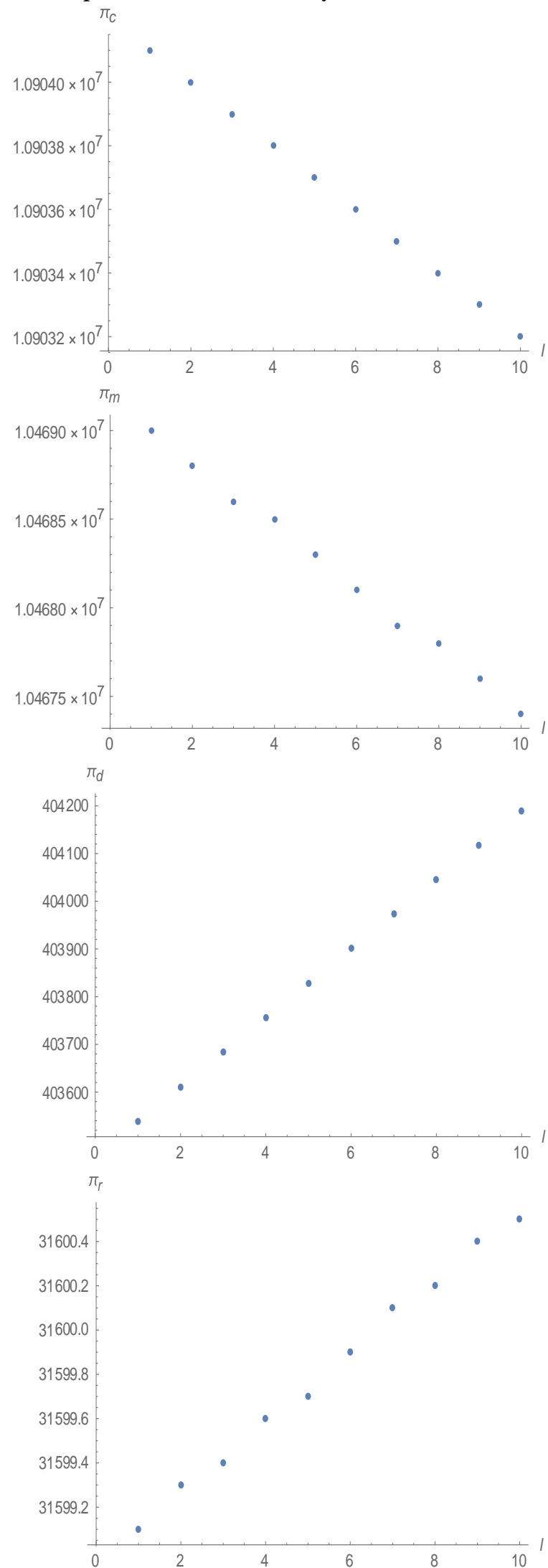

Gambar 1. Analisis sensitivitas $(l)$ terhadap keuntungan optimal total, produsen, distributor, dan pengecer. 


\section{UCAPAN TERIMA KASIH}

Penulis menyampaikan terima kasih kepada Universitas Sebelas Maret, Surakarta atas dukungannya terhadap penelitian civitas akademika Universitas Sebelas Maret.

\section{REFERENSI}

[1] Batarfi, R., Mohamad, H. J., Zanoni, S. 2016. DualChannel Supply Chain: a Strategy to Maximize Profit. Applied Mathematical Modelling, 40, hal.9454-9473.

[2] Bilgen, B. 2010. Application of Fuzzy Mathematical Programming Approach to The Production Allocation and Distribution Supply Chain Network Problem, Expert Systems with Applications, 37(6), hal. 4488-4495.

[3] Chen, J., Zhang, H., Sun, Y., 2012. Implementing Coordination Contracts in a Manufacturer Stackelberg Dual-Channel Supply Chain. Omega, 40(5), hal.571-583.

[4] Choi, S., 2003. Expanding To Direct Channel: Market Coverage as Entry Barrier. Journal of Interactive Marketing, 17 (1), hal. 25-40.

[5] Hanover, D., 1999. Its Not a Threat Just a Promise. Chain Storage Age, 75 (9), hal. 176.

[6] Hua, G. S. W. T., 2010. Price and Lead Time Decisions in Dual-Channel Supply Chains. European Journal of Operational Research, 205, hal. 113-126.

[7] Kumar, N. dan R. Kumar., 2013. Closed-Loop Supply Chain Management and Reverse Logistics-a Literature Review. Journal of Engineering Research and Technology, 6, hal. 455-468.

[8] Linton, J.D., Klassen, R., Jayaraman, V., 2007. Sustainable Supply Chains: an Introduction. J. Oper. Manag, 25, hal.1075-1082.

[9] Modak, N. M., Panda, S., Sana, S. S., 2015. Channel Coordination, Pricing and Replenishment Policies in Three-Echelon Dual-Channel Supply Chain. Control Cybernetics, 44(4), hal.481-518.

[10] Pekgun P, Griffin PM, Keskinocak P., 2008. Coordination of Marketing and Production for Price and Lead Time Decisions. IIE Trans, 40 (1), hal. 1230.

[11] Saha, S., Sarmah, S.P., \& Modak, N.M., 2018. Single Versus Dual-Channel: a Strategic Analysis in Perspective of Pengecer's Profitability Under ThreeLevel Dual-Channel Supply Chain. Asia Pacific Management Review, 23, hal. 148-160.

[12] Zhang, Z. Z., Zong, J. W., \& Li, W. L., 2015. Retail Services and Pricing Decisions in a Closed-Loop Supply Chain with Remanufacturing. Sustainability, 7, hal. 2373-2396.

[13] Urban, G., Sultan, F., Qualls, W., 200o. Placing Trust at The Center of Your Internet Strategy. Sloan Management Review, 42, hal.39-48. 